\title{
An Integrin-Contactin Complex Regulates CNS Myelination by Differential Fyn Phosphorylation
}

\author{
Lisbeth Schmidt Laursen, ${ }^{1}$ Colin W. Chan, ${ }^{2}$ and Charles ffrench-Constant ${ }^{1}$ \\ ${ }^{1}$ Medical Research Council Centre for Regenerative Medicine and Multiple Sclerosis Society Translational Research Initiative, Centre for Inflammation \\ Research, The Queen's Medical Research Institute, University of Edinburgh, EH16 4TJ Edinburgh, United Kingdom, and ²Department of Pathology, \\ University of Cambridge, CB2 1QP Cambridge, United Kingdom
}

The understanding of how adhesion molecules mediate the axon-glial interactions in the CNS that ensure target-dependent survival of oligodendrocytes and initiate myelination remains incomplete. Here, we investigate how signals from adhesion molecules can be integrated to regulate these initial steps of myelination. We first demonstrate that the Ig superfamily molecule contactin is associated in oligodendrocytes with integrins, extracellular matrix receptors that regulate target-dependent survival by amplification of growth factor signaling. This amplification is inhibited by small interfering RNA-mediated knockdown of contactin in oligodendrocytes. In contrast, the presence of L1-Fc, the extracellular portion of a contactin ligand expressed on axons, enhanced survival and additionally promoted myelination in cocultures of neurons and oligodendrocytes. We further demonstrate that the signals from contactin and integrin are integrated by differential phosphorylation of the Src family kinase Fyn. Integrin induced dephosphorylation of the inhibitory Tyr-531, whereas contactin increased phosphorylation of both Tyr-531 and the activating Tyr-420. The combined effect is an enhanced activity of Fyn and also a dynamic regulation of the phosphorylation/dephosphorylation balance of Fyn, as required for normal cell adhesion and spreading. We conclude, therefore, that a novel integrin/contactin complex coordinates signals from extracellular matrix and the axonal surface to regulate both oligodendrocyte survival and myelination by controlling Fyn activity.

\section{Introduction}

In the CNS, each oligodendrocyte extends multiple processes that contact and wrap around the axon to form the myelin sheath. Because the thickness of a single sheath (i.e., the number of wraps) is precisely related to axon diameter, each interaction provides the regulation required to form the correct amount of myelin. How such local regulation is achieved by the axon-glial interaction is unknown. In contrast to the peripheral nervous system, in which the level of neuregulin 1 type III instructs the thickness of the myelin sheath generated by a Schwann cell (Michailov et al., 2004; Taveggia et al., 2005), no single molecule has been shown to have such an instructive role in the CNS. It is known from knock-out studies, however, that the Src family kinase Fyn regulates myelination by oligodendrocytes (Umemori et al., 1994; Sperber et al., 2001; Goto et al., 2008). Src family kinases are activated in a series of steps, involving protein-protein interactions and regulatory phosphorylation and dephosphorylation

Received Dec. 12, 2008; revised April 20, 2009; accepted June 4, 2009.

This work was funded by a Wellcome Trust Programme grant (C.ff.-C.), the Multiple Sclerosis Society of Great Britain and Northern Ireland, fellowships from the Alfred Benzon Foundation and the Danish Medical Research Council (L.S.L.), and a Biotechnology and Biological Sciences Research Council Collaborative Awards in Science and Engineering studentship (C.W.C.). We are very grateful to Dr. Jacky Trotter for sharing reagents and expertise and to Dr. Kathryn Lilley at the Cambridge University Proteomics Facility.

Correspondence should be addressed to Lisbeth Schmidt Laursen, Centre for Inflammation Research, The Queen's Medical Research Institute, University of Edinburgh, 47 Little France Crescent, EH16 4TJ Edinburgh, UK. E-mail: Is.laursen@ed.ac.uk.

DOI:10.1523/JNEUROSCI.5942-08.2009

Copyright (C) 2009 Society for Neuroscience $\quad 0270-6474 / 09 / 299174-12 \$ 15.00 / 0$ of two tyrosines: an activating tyrosine (Tyr-420 of rat Fyn) in the activation loop of the kinase domain, and an inhibitory tyrosine (Tyr-531) in the C-terminal tail that when phosphorylated binds to the Src homology 2 domain to prevent substrate binding (Hubbard, 1999; Gonfloni et al., 2000). This dual regulation implies the presence of distinct upstream signals that control each phosphorylation event, which in turn suggests the hypothesis that oligodendrocyte development and maturation during CNS myelination is regulated by the integration of signals resulting from complex axon-glial interactions rather than a single receptor-ligand pair.

A key step in this process of development and maturation, known to be regulated by axon-glial interaction, is oligodendrocyte survival. The numbers of newly formed oligodendrocytes exceeds that required for normal myelination, and only oligodendrocytes that establish contact with axons survive (Barres et al., 1993; Trapp et al., 1997). This is an example of target-dependent survival, which is partly controlled by a limited supply of the growth factor PDGF (Barres et al., 1992). Both $\alpha 6$ - and $\beta 1$ integrin knock-out mice show increased death of oligodendrocytes during development (Colognato et al., 2002; Benninger et al., 2006), and integrin binding to laminins, present in the extracellular matrix (ECM) surrounding axons, increases survival at low growth factor concentrations (Frost et al., 1999). These results support a model in which integrins, by shifting the doseresponse curve toward oligodendrocyte survival at lower growth factor concentrations, ensure that only oligodendrocytes contacting axons survive (Colognato et al., 2002). This survival effect 
A

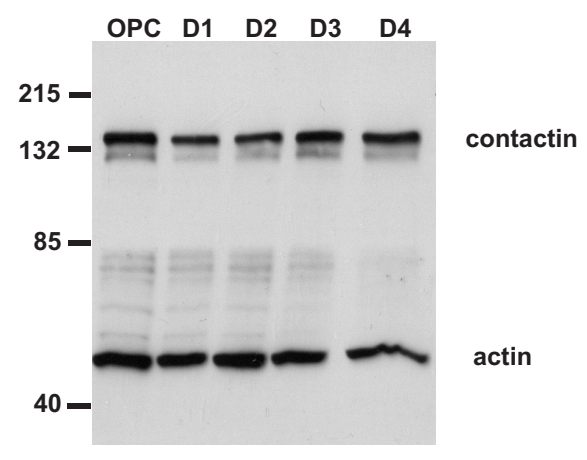

B
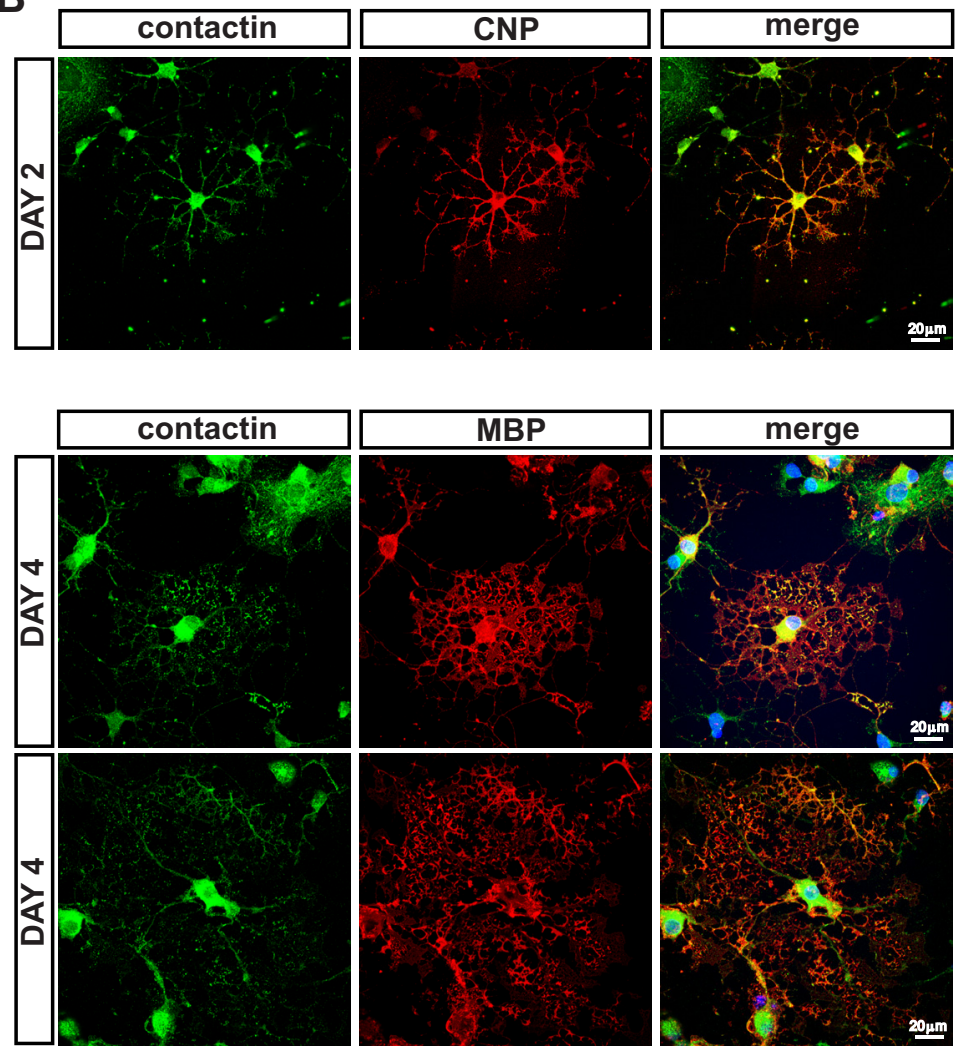

Figure 1. Contactin expression in oligodendrocytes. $A$, Western blot for contactin expression in OPCs at the time of plating or after differentiation for 1, 2, 3, or $4 \mathrm{~d}$ (D1-D4) after growth factor withdrawal. Actin is shown as a loading control. $\boldsymbol{B}$, Top row Oligodendrocytes were differentiated for $2 \mathrm{~d}$ and immunostained to show contactin (green) and a marker of newly differentiated oligodendrocytes (CNP) (red). Two bottom rows, Oligodendrocytes were differentiated for $4 \mathrm{~d}$ and immunostained to show contactin (green) and a marker of more differentiated oligodendrocytes (MBP) (red).

of integrins in oligodendrocytes is mediated, in part, through dephosphorylation of the negative regulatory site in Fyn (Colognato et al., 2004). However, maximal Fyn activity also requires phosphorylation of the positive regulatory site, and the integrative signaling hypothesis, described above, predicts that this is regulated by a second oligodendroglial receptor within the complex of proteins containing the integrin. To test this hypothesis and to elucidate the signaling mechanisms that underlie the initial stages of myelination, we initiated our studies by using a proteomic approach to identify oligodendrocyte proteins associated with $\alpha 6 \beta 1$-integrin.

\section{Materials and Methods}

Oligodendrocyte cell culture. Dissociated rat neonatal cortices were cultured at $37^{\circ} \mathrm{C}$ in $7.5 \% \mathrm{CO}_{2}$ in DMEM with $10 \%$ FCS and penicillin/ streptomycin on poly-D-lysine (PDL)-coated flasks. By day 10, cultures consist of oligodendrocyte precursors (OPCs) and microglia growing on an astrocyte monolayer (so-called mixed glial cultures). Purified oligodendrocyte precursor cells were acquired by mechanically shaking them off the surface of the astrocytes and then removing microglia by differential adhesion using a modified version of a previously described method (McCarthy and de Vellis, 1980). This technique generates a population of precursors cells of which $\sim 95 \%$ will differentiate into oligodendrocytes (Milner and ffrench-Constant, 1994).

Myelinating cocultures. This culture system is a modification of that described previously (Chan et al., 2004; Wang et al., 2007) In brief, embryonic DRG neurons were isolated from embryonic day $15-16$ rats and dissociated with papain (1.2 U/ml; Worthington), L-cysteine $(0.24 \mathrm{mg} / \mathrm{ml}$; Sigma $)$, and DNase I $(0.40 \mathrm{mg} / \mathrm{ml}$; Sigma) for $60 \mathrm{~min}$ at $37^{\circ} \mathrm{C}$. The dissociated cells were plated at a density of 150,000 cells per coverslip $(22 \mathrm{~mm})$ coated with PDL and growth factor-reduced Matrigel (BD Biosciences). The neurons were then cultured for $15 \mathrm{~d}$ in DMEM (Sigma) and 10\% FCS (Invitrogen) in the presence of nerve growth factor $(100 \mathrm{ng} / \mathrm{ml}$; Serotec). To remove contaminating cells, the cultures were pulsed three times for $2 \mathrm{~d}$ each with fluorodeoxyuridine (10 IU; Sigma) at days 2, 5, and 8 after seeding. After $15 \mathrm{~d}$, the medium was changed to a 50:50 mixture of Sato's modification of DMEM (SATO) (Bottenstein and Sato, 1979) and Neurobasal medium (Invitrogen), supplemented with 1\% B27 (Invitrogen), $\mathrm{N}$-acetyl cysteine $(5 \mu \mathrm{g} / \mathrm{ml}$; Sigma), and D-biotin $(10 \mathrm{ng} / \mathrm{ml})$. Oligodendrocyte precursor cells were generated as described above and then seeded onto the neurons at a density of 150,000 per coverslip. In experiments using L1-Fc or Fc control, these were added at this time. Cocultures were maintained for $21 \mathrm{~d}$ with media changes and (if used) fresh L1-Fc or Fc control every 3 d. In experiments using $\beta 1$ blocking antibodies (Ha2/5; BD Pharmingen) or control antibodies, these were added after $24 \mathrm{~h}$, and media were changed every $2 \mathrm{~d}$ adding fresh antibodies.

For analysis, cells were fixed in $4 \%$ paraformaldehyde in PBS for 15 min and permeabilized with PBS containing 40\% normal goat serum (Sigma) and $0.4 \%$ Triton X-100. The cultures were immunolabeled with primary antibodies against myelin basic protein (MBP) at 1:100 (Serotec), and neurofilament at 1:1000 (Sigma), followed by detection with secondary antibodies conjugated with Alexa 488 (Invitrogen) used at a 1:500 dilution and 7-amino-4-methylcoumarin-3-acetic acid (Jackson ImmunoResearch) used at 1:100. Twelve random pictures were taken of areas with no less than $70 \%$ axonal coverage, by choosing a starting point of sufficient axonal coverage and moving across the coverslip in steps of $2 \mathrm{~mm}$. The number of MBP-positive cells was counted, analyzing at least 200 cells per coverslip, and were scored as myelinating oligodendrocytes when at least two internodes could be connected to a cell body. An internode was defined as a smooth tube of MBP staining surrounding an axon. Two coverslips for each condition in at least three independent experiments were analyzed. The mean was calculated and expressed \pm SD. Statistical significance was determined using one-way ANOVA, followed by a Dunnett's test. 
Micrographs for analysis were taken using an Axioplan Fluorescence microscope (Carl Zeiss) using a $20 \times$ [numerical aperture (NA) 0.5] objective. Images were acquired with a CCD camera (C4742-95; Hamamatsu) using Openlab imaging software or using a Leica SPE confocal microscope with $10 \times(\mathrm{NA} 0.30), 20 \times(\mathrm{NA} 0.70)$, and $63 \times(\mathrm{NA}$ 1.30) objectives using the software of the manufacturer.

Colocalization analysis. Colocalization of contactin and $\beta 1$-integrin was assessed after immunostaining as detailed above. Confocal $z$-stacks acquired using a Leica SPE confocal microscope equipped with a $63 \times$ objective (NA 1.30) were analyzed using the JACoP plugin for NIH Image J (Bolte and Cordelieres, 2006). For each condition, 15 cells were analyzed.

Transfection of small interfering RNA. Mixed glial cultures at day 10 were transfected using Lipofectamine 2000 (Invitrogen) for $6 \mathrm{~h}$ with control and contactin small interfering RNA (siRNA) duplexes, using 20 $\mu \mathrm{l}$ of a $20 \mathrm{pmol} / \mu \mathrm{l}$ solution per $75 \mathrm{~cm}^{2}$ flask. The transfection was repeated at day 2 , after which the oligodendrocyte precursors were harvested as above and plated in eight-well chamber slides in SATO medium with $0.5 \%$ FCS for terminal deoxynucleotidyl transferase-mediated biotinylated UTP nick end labeling (TUNEL) assays or in six-well plates for protein assays. The siRNA sequences used for knockdown were as follows: contactin, (1) 5'-ACUUCGACUACGUACUCUCUU-3', (2) $5^{\prime}$ UUGAUAACAAGGUUCCCUCUU-3', (3) 5' -AUUGGUAACGGUCACUUUCUU-3', and (4) 5'-UCAUUGAUAUGCUCUACCUU-3'; Fyn, (1) 5'-UGACCUCCAUCCCGAACUA-3', (2) AGAGGUACCUUUCUUAUCC-3', (3) 5'-GUAGUUCCCUGUCACAAAG-3', and (4) 5' UCGAACGCAUGAAUUAUAU- $3^{\prime}$; and neural cell adhesion molecule (NCAM), (1) 5'-GACACUAUCUGGUCAAGUA-3', (2) 5' -GAAGGGUCCUGUAGAAACA-3', (3) 5'-GUACGAAGUAUAUGUGGUA-3', and (4) 5'-ACAGCAAUAUCAAGAUCUA-3' (all from Dharmacon). For control duplexes, ON-TARGETplus Non-targeting Pool (Dharmacon) was used.

Survival assay. Eight-well chamber slides were coated with PDL (5 $\mu \mathrm{g} / \mathrm{ml}$ ) overnight at room temperature, washed in water, coated with laminin-2 $(10 \mu \mathrm{g} / \mathrm{ml})$ purified from human placenta (Sigma) for $4 \mathrm{~h}$ at $37^{\circ} \mathrm{C}$, and then washed three times in PBS. Twenty-five thousand oligodendrocyte precursor cells suspended in SATO with $0.5 \%$ FCS were plated in each well, and, $1 \mathrm{~h}$ after attachment, PDGF at $0,0.1,1$, or 10 $\mathrm{ng} / \mathrm{ml}$ and/or L1-Fc $(1 \mu \mathrm{g} / \mathrm{mL})$ was added. The cells were then allowed to differentiate for $3 \mathrm{~d}$. Immunostaining for galactosylcerebroside (GalC) was used to identify newly formed oligodendrocytes, and apoptotic cells were visualized by detection of fragmented DNA by ApopTag (Millipore Bioscience Research Reagents). For each condition, 12 random pictures were taken with analysis of a minimum of 300 cells in each of three independent experiments. To compare different experiments, the percentage of cell death was normalized to the control value of cells plated on PDL without any addition of PDGF, and the mean \pm SD percentages were calculated. Statistical significance was analyzed as above.

Western blotting and protein analysis. Cells were washed in ice-cold PBS and lysed in 1\% Triton X-100, 10 mM Tris, pH 7.4, 5 mM EDTA, and 150 $\mathrm{mm} \mathrm{NaCl}$ on ice for $15 \mathrm{~min}$. The cells were scraped off and transferred to Eppendorf tubes. Lysates were centrifuged at 13,200 rpm to separate detergent-insoluble and detergent-soluble material. The Triton X-100 insoluble fractions were then solubilized in 1\% SDS, $10 \mathrm{~mm}$ Tris, and 150 $\mathrm{mm} \mathrm{NaCl}$. Proteins were separated by SDS-PAGE using 7.5\% acrylamide minigels (Bio-Rad) and blotted onto polyvinylidene difluoride membrane (Millipore Corporation). Membranes were dried and blocked in $2 \%$ Tween 20 for $10 \mathrm{~min}$, followed by overnight incubation with primary antibodies in TBS with $0.1 \%$ Tween 20 (TBS-T). Membranes were washed in TBS-T and incubated for $1 \mathrm{~h}$ with HRP-conjugated secondary antibodies (GE Healthcare), washed again in TBS-T, and developed with ECL-plus (GE Healthcare).

Immunoprecipitation. For immunoprecipitation, lysates were prepared as described above and incubated with antibodies on protein A/G beads (Santa Cruz Biotechnology) at $4^{\circ} \mathrm{C}$ for $4 \mathrm{~h}$.

For immunoprecipitation the $\alpha 6 \beta 1$ antibodies or control IgG was crosslinked to the protein A/G beads. $\alpha 6 \beta 1$ antibodies (MAB1410; subunit specificity unknown; Millipore Bioscience Research Reagents) were incubated with protein $\mathrm{A} / \mathrm{G}$ beads for $2 \mathrm{~h}$ at $4^{\circ} \mathrm{C}$ and washed three times

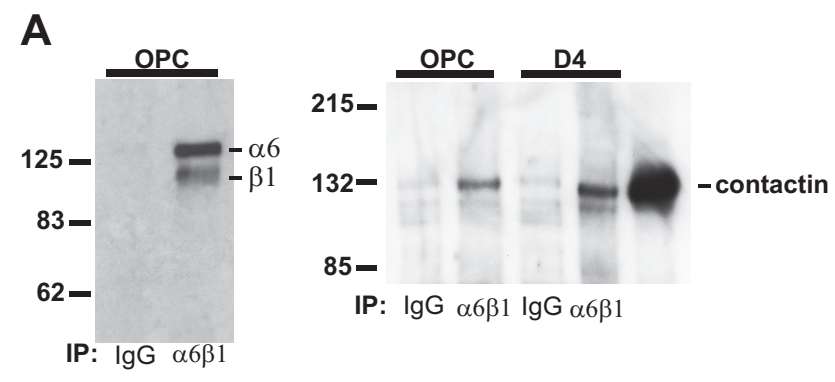

WB: streptavidin

WB: contactin

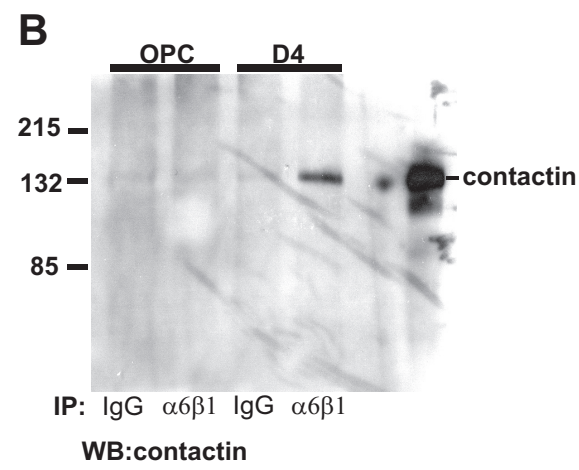

Figure 2. Coimmunoprecipitation of contactin and $\alpha 6 \beta 1$-integrin. $\boldsymbol{A}$, Left, $\alpha 6 \beta 1$-Integrin immunoprecipitation (IP) after cell surface biotinylation of OPCS and detection by HRPconjugated streptavidin, showing that proteins of molecular weight corresponding to that of the $\alpha 6$ - and $\beta 1$-integrin subunits are precipitated. Right, Western blot (WB) using a contactin antibody after coimmunoprecipitation of cell lysates from OPCs or from mature oligodendrocytes (D4), with $\alpha 6 \beta 1$-integrin antibodies or control antibodies. Right-hand lane here and in $\boldsymbol{B}$, Lysate prior to immunoprecipitation to show the position of the contactin band. $\boldsymbol{B}$, Western blot using a contactin antibody after coimmunoprecipitation of cell lysates from OPCS or from mature oligodendrocytes (D4), in RIPA buffer, with $\alpha 6 \beta 1$ or control antibodies.

with $200 \mathrm{~mm}$ sodium borate, pH 9. Freshly dissolved $20 \mathrm{~mm}$ dimethylpimelimidate-dihydrochloride $(1 \mathrm{ml})$ in $200 \mathrm{~mm}$ sodium borate was added to the antibody/protein $\mathrm{A} / \mathrm{G}$ beads and incubated at room temperature for $30 \mathrm{~min}$. Crosslinking was quenched by three successive washes in $100 \mathrm{~mm}$ glycine, $\mathrm{pH}$ 3. Beads were rinsed three times in PBS before use for immunoprecipitation. To verify specificity of the $\alpha 6 \beta 1$ antibody used for the pull-down experiment, Western blot analysis was performed using cell lysates of biotinylated oligodendrocytes followed by detection with streptavidin. For biotinylation of cell surface proteins, oligodendrocytes were washed three times in PBS, $\mathrm{pH}$ 8.0, and incubated with $2 \mathrm{~mm}$ sulfo-NHS-biotin (Thermo Fisher Scientific) for $30 \mathrm{~min}$ at $37^{\circ} \mathrm{C}$. The reaction was quenched by three successive washes in PBS/100 mm glycine, and the cells were lysed as described above.

Mass spectrometry. Protein samples were separated by SDS-PAGE, bands were excised after staining with SyproRuby protein gel stain (PerkinElmer Life and Analytical Sciences), and peptides were extracted after tryptic digestion (Promega), reduction, and carboxyamidomethylation. Peptides were separated using a capillary LC system (Waters) with a PepMap C18 reversed-phase column (LC Packings), attached to a QTOF2 mass spectrometer (Waters), or the same column on a Dionax Dual Gradient LC system, attached to a QSTAR XL instrument (Applied Biosystems). The tandem mass spectrometry fragmentation data gathered was used to search the National Center for Biotechnology Information database using the MASCOT search engine. Mascot Scores with $p<0.05$ for random occurrence were considered significant and are listed in supplemental Table S1 (available at www.jneurosci.org as supplemental material).

Antibodies and reagents. All reagents were obtained from Sigma, unless otherwise stated. The $\beta 1$-integrin antibody for immunocytochemistry (mAB 1997) and immunoprecipitation (mAb 1410), $\alpha 6$-integrin antibody for immunocytochemistry (GoH3), and the NCAM antibody 

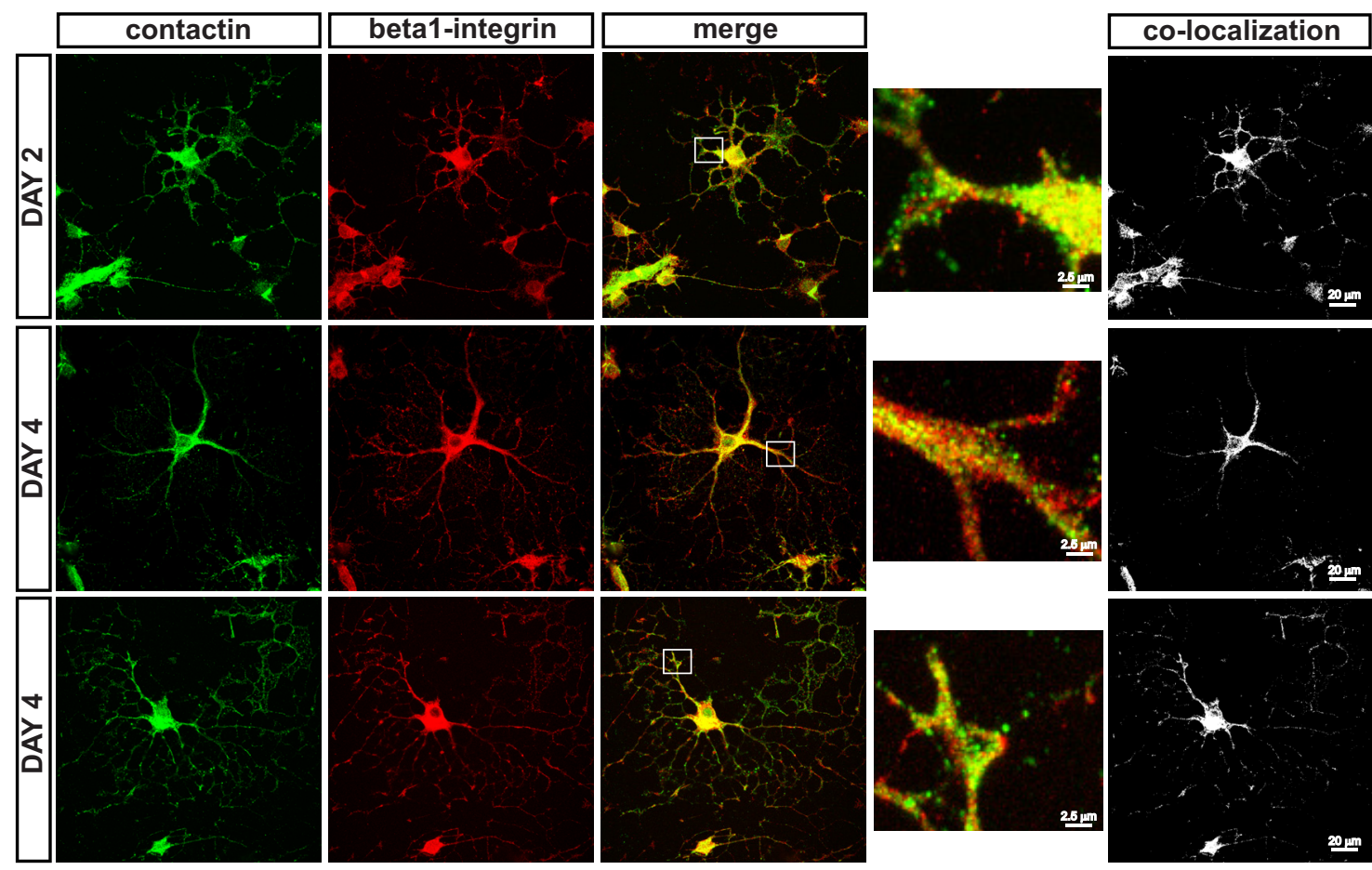

Figure 3. $\alpha 6 \beta 1$-Integrin and contactin colocalize in oligodendrocytes. Top, Oligodendrocytes differentiated for $2 \mathrm{~d}$ in culture after growth factor withdrawal and then fixed and immunolabeled to show contactin (green) and $\beta 1$-integrin (red). Colocalization is depicted in yellow, and the boxed region is shown at higher magnification $(8 \times)$ to the right. The right shows colocalization in white. Middle and bottom, Oligodendrocytes differentiated for $4 \mathrm{~d}$ and then immunolabeled to show contactin (green) and $\beta 1$-integrin (red). Colocalization is depicted in yellow, and the boxed regions are shown at higher magnification $(8 \times)$ to the right. The right shows colocalization in white.

(AB5032) were from Millipore Bioscience Research Reagents. The $\beta 1$ integrin blocking antibody and the isotype control antibody were from BD Biosciences. The 2', 3' -cyclic nucleotide 3' -phosphodiesterase (CNP) antibody for immunocytochemistry was from Sigma. The Fyn antibody was from BD Biosciences, and the phospho-tyrosine-specific antibodies against PY418 and PY527 were from Invitrogen. Contactin antibodies were obtained from Santa Cruz Biotechnology [for Western blotting and immunocytochemistry (sc-20297); or were a kind gift from Dr. J. Trotter (University of Mainz, Mainz, Germany)] (Krämer et al., 1997). All secondary antibodies were from Invitrogen or Jackson ImmunoResearch.

\section{Results}

\section{Identification of contactin as a novel} integrin-associated protein

Proteins associated with $\alpha 6 \beta 1$-integrin were immunoprecipitated from lysates of mixed glial cultures after extraction with $1 \%$ Triton $\mathrm{X}-100$ at $4^{\circ} \mathrm{C}$ and then separated by denaturing onedimensional PAGE. Individual bands were excised from the gel, digested by trypsin, and identified by mass spectrometry. The resulting set of proteins included contactin, a glycosylphosphatidylinositol (GPI)-anchored member of the Ig family of cell adhesion molecules, identifying this protein as a novel integrinassociated molecule (supplemental Table 1, available at www. jneurosci.org as supplemental material). Previously, expression of contactin has been observed in neurons (Ranscht, 1988; Gennarini et al., 1989; De Benedictis et al., 2006), and oligodendrocytes (Krämer et al., 1997; De Benedictis et al., 2006), and Western blot analysis of lysates from oligodendrocyte precursors, differentiated from 0 to $4 \mathrm{~d}$ in culture, confirmed the expression of contactin in both precursors and differentiated cells (Fig. 1A). In primary rat oligodendrocytes, immunocytochemical staining for contactin, in combination with the oligodendrocyte markers $\mathrm{CNP}$ and MBP, showed that contactin was localized to both the cell body and the processes at the different developmental stages (Fig. $1 B$ ).

\section{Association and colocalization of $\beta 1$-integrin and contactin in oligodendrocytes}

To confirm the interaction between $\beta 1$-integrin and contactin, we performed coimmunoprecipitation and colocalization studies. For coimmunoprecipitation, lysates from both precursor cells and differentiated oligodendrocytes were prepared with either Triton X-100 or the SDS-containing (and hence more stringent) radioimmunoprecipitation assay (RIPA) buffer. In the Triton X-100 extracts, contactin was found to coimmunoprecipitate with $\alpha 6 \beta 1$-integrin in both precursors and differentiated cells (Fig. $2 A$ ). Interestingly, in lysates from mature oligodendrocytes, but not in precursor cells, the contactin- $\alpha 6 \beta 1$-integrin interaction resisted washing in RIPA buffer (Fig. $2 B$ ). These results indicate a specific interaction and suggest that a change in the interaction occurs as the oligodendrocytes differentiate.

Colocalization studies were performed in mouse oligodendrocytes. In partially differentiated oligodendrocytes with only a few major processes, partial colocalization of contactin and $\beta 1$ integrin was observed in the cell body and the processes (Fig. 3). In contrast, two different, but equally abundant, patterns of colocalization were seen in more differentiated oligodendrocytes having multiple processes and forming myelin sheaths in culture. Both patterns showed partial colocalization in the cell body and in the main processes, whereas in approximately half of the cells, colocalization was also observed in the minor processes and the myelin sheaths. Similar patterns were observed with oligodendrocytes double stained with contactin and $\alpha 6$-integrin antibodies (data not shown). Importantly, the level of colocalization was similar for cells cultured on PDL and laminin. In both cases, 
A
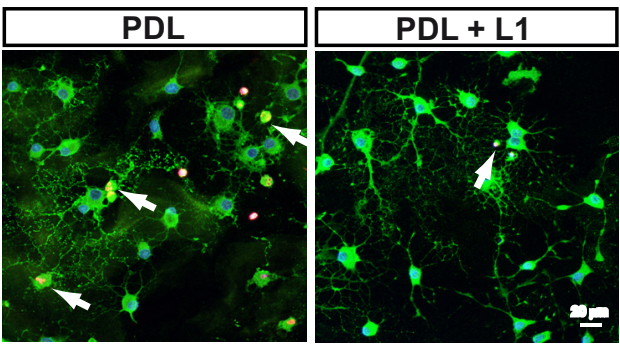

B
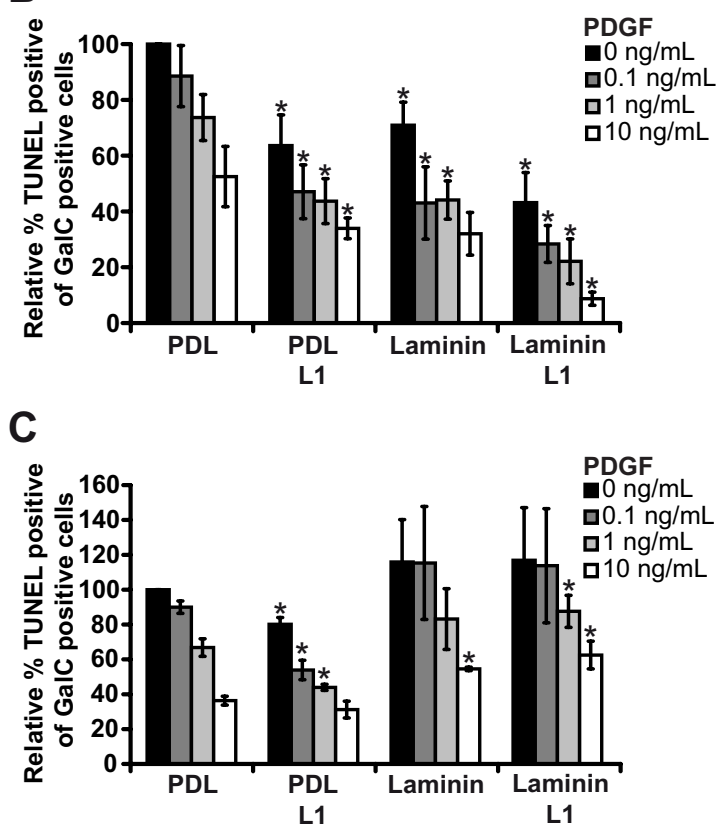

Figure 4. Contactin and L1 act synergistically with integrin and growth factor signaling to enhance oligodendrocyte survival. Oligodendrocyte precursors were differentiated for $3 \mathrm{~d}$ on PDL or laminin in the presence of increasing concentrations of PDGF $(0,0.1,1$, or 10 $\mathrm{ng} / \mathrm{ml})$ and in the absence or presence of $\mathrm{L} 1-\mathrm{Fc}(1 \mu \mathrm{g} / \mathrm{ml})$. $A$, Immunolabeling against GalC followed by TUNEL assay reveals newly formed, apoptotic oligodendrocytes (arrowheads). $\boldsymbol{B}$, Survival was quantitated using a TUNEL assay. The numbers of TUNEL-positive/ GalC-positive cells are shown as a percentage relative to the control condition, under which cells were plated on PDL without PDGF. The PDGF concentrations are as indicated: 0 , black; $0.1 \mathrm{ng} / \mathrm{ml}$, dark gray; $1 \mathrm{ng} / \mathrm{ml}$, light gray; $10 \mathrm{ng} / \mathrm{ml}$, white. Both laminin and L1 amplify PDGF-mediated oligodendrocyte survival, and the additive effect of the L1 and laminin leads to an additional amplification of survival. $\boldsymbol{C}, A s$ in $\boldsymbol{B}$, but the experiment was performed in the presence of blocking antibodies against $\beta 1$-integrin $(2 \mu \mathrm{g} / \mathrm{ml})$. Note that the blocking antibody has no effect on the amplification by L1 but blocks amplification by both laminin and the combination of laminin and L1. ${ }^{*} p<0.05$.

$\sim 40 \%$ of the contactin colocalized with $\beta 1$-integrin (PDL, $38.3 \pm 6.9 \%$; laminin, $43.8 \pm 7.6 \%$ ), and $25 \%$ of the $\beta 1$ integrin colocalized with contactin (PDL, $25.9 \pm 5.7 \%$; laminin, $24.5 \pm 4.7 \%)$. The finding that only a proportion of integrin and contactin are associated at any time suggests that each may have additional roles and interactions, in keeping with the concept that such signaling complexes are dynamic in nature.

The colocalization of $\beta 1$-integrin and contactin in oligodendrocytes was analyzed further in cocultures of oligodendrocytes and DRG neurons in which individual myelinating cells could be seen. At day 3, before myelination, colocalization is observed in the cell body and processes, including the region of the processes in which interaction with the axons is seen (supplemental Fig. S1, available at www.jneurosci.org as
A

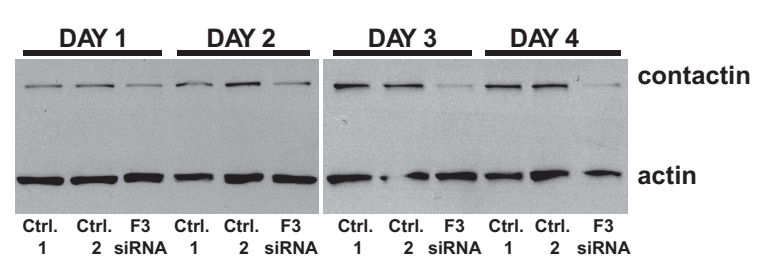

B
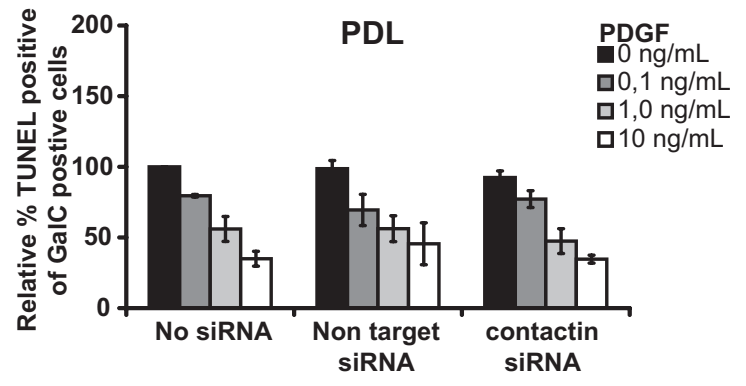

C

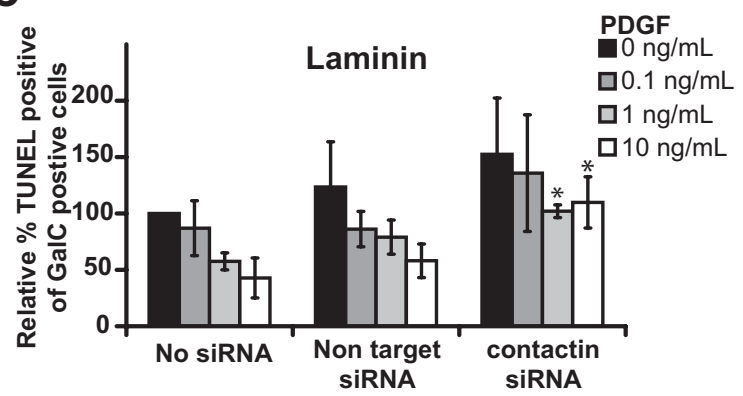

D

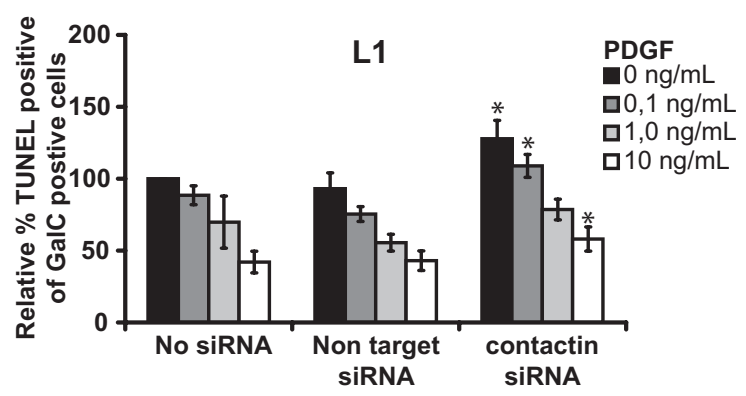

Figure 5. Contactin is required for integrin- and L1-mediated oligodendrocyte survival. $\boldsymbol{A}$, Contactin expression in cultured OPCS 1-4 d after transfection with control and contactin (F3) siRNAs. Note that the contactin siRNAs reduce protein expression at all time points. $\boldsymbol{B}$, Survival of OPCs transfected with contactin or control siRNA duplexes and analyzed as in Figure 4. Note that contactin knockdown has no effect on PDGF-mediated oligodendrocyte survival. $\boldsymbol{C}$, As in $\boldsymbol{B}$ but with cells cultured on laminin. Note that contactin knockdown inhibits the survival effect of laminin. $\boldsymbol{D}$, As in $\boldsymbol{B}$ but with cells treated with $1 \mu \mathrm{g} / \mathrm{ml} \mathrm{L1-Fc.} \mathrm{Note} \mathrm{that} \mathrm{contactin} \mathrm{knockdown}$ inhibits the survival effect of $L 1$. Survival levels have been normalized on each substrate to control without siRNA and PDGF. ${ }^{*} p<0.05$.

supplemental material). At day 9, after the formation of the first myelin sheaths, intense staining of $\beta 1$-integrin is observed along MBP-positive internodes, which also show an increased concentration of contactin (supplemental Fig. S1, available at www.jneurosci.org as supplemental material). However, whether this represents oligodendrocyte or neuronal contactin cannot be determined, because contactin is also expressed in the neurons.

Together, these results demonstrate that $\alpha 6 \beta 1$-integrin and 
A
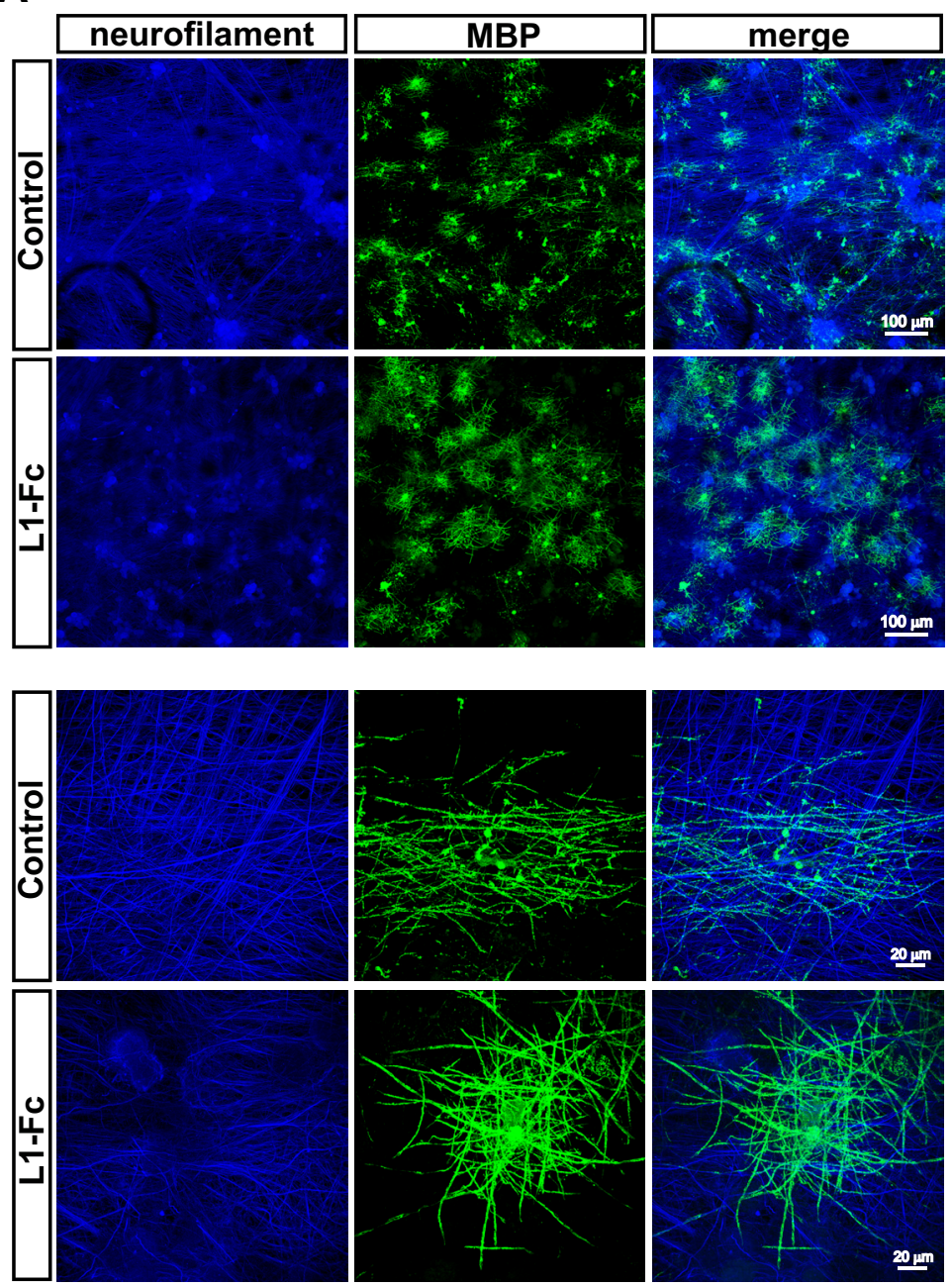

\section{B}

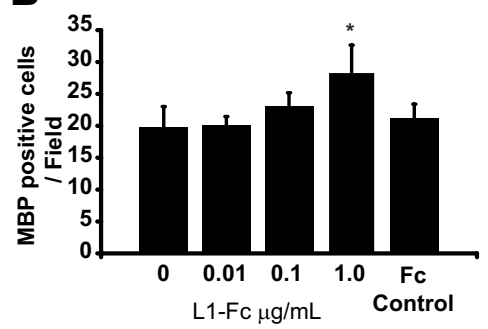

C

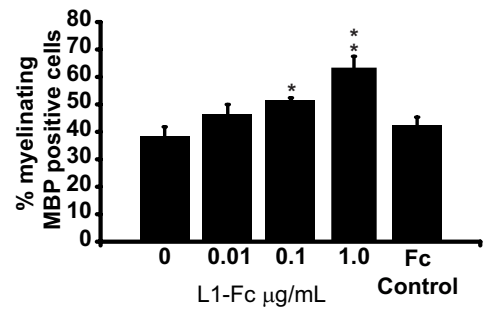

Figure 6. L1 enhances oligodendrocyte survival and myelination. $\boldsymbol{A}$, Untreated or L1-Fc-treated cocultures of oligodendrocytes and DRG neurons. The cells were immunolabeled for MBP (green) and neurofilament (blue) and shown at low ( 2 top panels) and high ( 2 bottom panels) magnification. $\boldsymbol{B}$ and $\boldsymbol{C}$ show the numbers of MBP-positive cells per field and the percentage of MBPpositive cells forming myelin internodes, respectively, at increasing concentrations of L1-Fc. ${ }^{*} p<0.05$; $^{* *} p<0.01$.

contactin are associated in a protein complex of the oligodendrocyte and that these might play a role in axon-glial contact.

\section{Contactin acts synergistically with integrin to amplify growth} factor survival signaling in oligodendrocytes

To establish the functional significance of the contactin-integrin interaction, the survival of newly formed oligodendrocytes in culture was assessed in the presence of activating ligands of either integrin or contactin or both. We first asked whether ligand binding to contactin would enhance the survival promoted by $\alpha 6 \beta 1$ integrin. Purified oligodendrocyte precursors, cultured on PDL or $\alpha 6 \beta 1$-binding laminin substrates, were exposed to increasing concentrations of PDGF in the absence or presence of L1, a known contactin ligand, presented as a soluble fusion protein with the Ig Fc domain. L1 is targeted specifically to the axonal surface of neurons in culture (van den Pol and Kim, 1993; Winckler et al., 1999), and the expression of L1 peaks around the onset of myelination in the developing brain (Martini and Schachner, 1986; Joosten and Gribnau, 1989). Therefore, $\mathrm{L} 1$ is a potential contactin ligand in vivo. We observed, in accordance with previous data (Frost et al., 1999), that PDGF induced a dose-dependent increase in survival that was amplified by laminin (Fig. $4 A, B)$. Stimulation of cells grown on PDL with the soluble L1-Fc chimera amplified survival, similarly to that observed for cells cultured on laminin. Of interest, an additive effect of L1, laminin, and PDGF was observed (Fig. 4A, B), suggesting that signals from soluble growth factors, ECM, and cell adhesion molecules on the axonal surface are integrated to enhance oligodendrocyte survival.

L1 has been reported previously to interact with other integrin receptors by means of its RGD motif. However, because $\alpha 6 \beta 1$-integrin does not bind ligands via this motif, it is unlikely that our results reflect an interaction between L1 and the integrin. To confirm the absence of such interaction, the experiments were performed in the presence of a $\beta 1$-specific blocking antibody, preventing ligandinduced integrin activation. In the presence of this antibody, increased survival was still observed in response to increasing levels of PDGF. The amplifying effect of L1 on this PDGF response was also still observed for cells cultured on PDL, demonstrating that L1 does not act directly through the integrin. For cells cultured on laminin, the survival effect of increasing levels of PDGF was not affected by the blocking antibody, but, as expected, the amplifying effect of laminin was abolished (Fig. 4C). Importantly, the additive effect of laminin and L1 was also abolished. Hence, survival levels did not exceed those seen with PDGF alone on PDL (Fig. 4C). We therefore conclude that, in the presence of integrin ligand, the enhanced survival effect of L1 becomes dependent on integrin activation.

\section{Contactin is required for integrin-mediated} oligodendrocyte survival

The additive effect of L1 and laminin on oligodendrocyte survival suggests that there is a functional interaction between contactin and integrin signaling. To test this hypothesis, we performed siRNA-mediated knockdown experiments. Purified oligodendrocyte precursors were transfected with a mixture of contactin RNA duplexes, and the efficiency of knockdown was tested at 
various time points after transfection. A reduction in the level of contactin was detectable by day 1 and was maintained until day 4 (Fig. 5A). To determine the effect of contactin knockdown on survival, transfected cells were switched $1 \mathrm{~d}$ after transfection into culture conditions that promote differentiation, so ensuring that contactin knockdown was maintained throughout the $3 \mathrm{~d}$ of differentiation. In cells transfected with contactin duplexes, the dose-dependent increase in survival after PDGF stimulation alone was still observed (Fig. 5B). Hence, contactin has no effect on survival induced by PDGF. In contrast, the amplified survival effect of PDGF when the cells were cultured on laminin (Fig. 5C) or stimulated with L1-Fc (Fig. 5D) was abolished by knockdown of contactin. In contrast, siRNA knockdown of another cell adhesion molecule, NCAM, had no effect PDGF induced survival or on laminin- and L1-induced survival amplification, confirming the specificity of contactin as a regulator of integrin signaling (supplemental Fig. S2, available at www. jneurosci.org as supplemental material).

Based on these results, we propose the existence of a novel signaling unit composed of oligodendroglial $\alpha 6 \beta 1$-integrin and contactin. Importantly, such a unit is essential for the transmission of survival amplification signals from both laminin and L1.

\section{Stimulation of the integrin-contactin complex enhances myelination}

A role of $\beta 1$-integrin and laminin in myelination has been suggested in recent reports (Chun et al., 2003; Lee et al., 2006). We therefore asked whether L1, in addition to the survival effects documented above, would also have a stimulatory effect on myelination. When myelinating cocultures of oligodendrocytes and DRG neurons (Wang et al., 2007) were treated with increasing concentrations of L1-Fc, a dose-dependent increase in the number of MBP-positive oligodendrocytes was observed (Fig. $6 A, B)$. In addition to the increase in cell number, a higher percentage of the MBP-positive cells were found to myelinate axons in the L1-Fc-treated cultures, with each oligodendrocyte also revealing a more compact appearance of the MBP-positive internodes. No effect on either the number of mature oligodendrocytes or myelination was observed when a similar concentration of control Fc was used (Fig. 6C), and the enhanced myelination observed in the L1-Fc-treated cultures was not attributable to a difference in axonal density because this was the same in the control and L1-Fc-treated cultures (data not shown).

To confirm that myelination induced by $\mathrm{L} 1$ is indeed dependent on interaction with the contactin-integrin complex, we analyzed the effect of $\mathrm{L} 1$ in the presence and absence of $\beta 1$ blocking antibodies. In the presence of the blocking antibody, but not an isotype control antibody, a significant decrease in myelination was observed (Fig. 7A-C). Addition of L1-Fc did not reverse this inhibitory effect, suggesting that an interaction between $\beta 1$-integrin and laminin is required for the L1-Fc-stimulated increase in myelination (Fig. 7C).

\section{Integrin and contactin signaling cooperate to regulate Fyn kinase activity}

Thus, our functional studies show that there is an interdependence of contactin and integrin in oligodendrocyte survival and myelination. But how are the signals from laminin and L1 integrated? Several experiments point to Fyn as a key regulator of myelination as well as oligodendrocyte survival: Fyn knock-out animals show region-specific hypomyelination (Sperber et al., 2001), and in vitro experiments have established that Fyn activation is important for morphological differentiation of oligodendrocytes (Colognato et al., 2004; Liang et al., 2004). We showed previously that Fyn is required for the transmission of survival signals from laminin (Colognato et al., 2004). To address whether Fyn also is required for transmission of L1-induced survival signals, siRNA-mediated knockdown of Fyn was performed in oligodendrocytes. In cells transfected with Fyn siRNA duplexes, the PDGF-induced survival was still observed (Fig. $8 \mathrm{~B}$ ). In contrast, the amplification of survival signals mediated by both laminin and L1 were abolished after Fyn knockdown, confirming the involvement of Fyn in this process (Fig. 8C, D).

Fyn is phosphorylated after antibody-induced contactin clustering (Krämer et al., 1997), but the identity of the tyrosine(s) targeted is unknown. In addition, laminin-mediated integrin signaling reduces phosphorylation of the inhibitory Tyr-531 in Fyn 
A

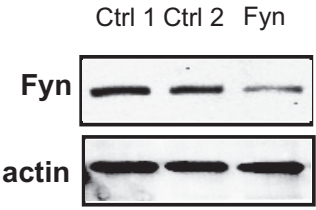

B

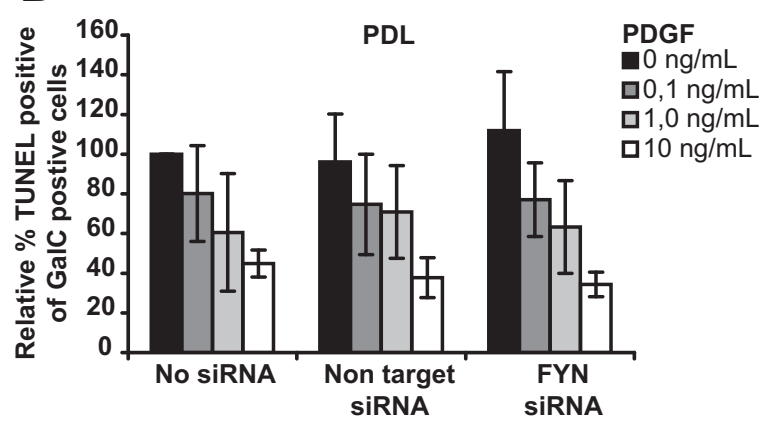

C
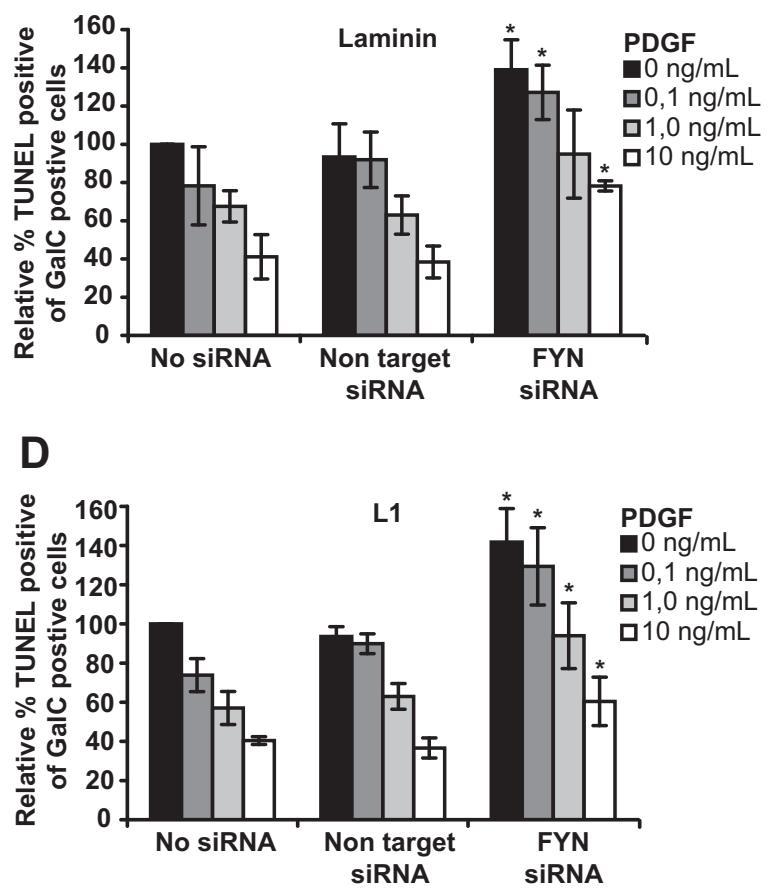

Figure 8. Fyn is required for laminin- and L1-induced oligodendrocyte survival. $A$, Fyn expression in cultured OPCs $3 \mathrm{~d}$ after transfection with control and Fyn siRNAs. Ctrl, Control. $\boldsymbol{B}$, Survival of OPCs transfected with Fyn or control siRNA duplexes and analyzed as in Figure 4. Note that Fyn knockdown has no effect on PDGF-mediated oligodendrocyte survival. $C$, As in $\boldsymbol{B}$ but with cells cultured on laminin. Note that Fyn knockdown inhibits the survival effect of laminin. $\boldsymbol{D}$, As in $\boldsymbol{B}$ but with cells treated with $1 \mu \mathrm{g} / \mathrm{ml} \mathrm{L1-Fc.} \mathrm{Note} \mathrm{that} \mathrm{Fyn} \mathrm{knockdown} \mathrm{inhibits} \mathrm{the}$ survival effect of $L 1$. Survival levels have been normalized on each substrate to control without siRNA and PDGF. ${ }^{*} p<0.05$.

but has no effect on phosphorylation of Tyr-420, required for kinase activation (Colognato et al., 2004). We reasoned that ligand-induced contactin clustering might target Tyr-420, so contributing to integration of signals that regulates Fyn activity. Therefore, we examined the phosphorylation status of Tyr-420 and Tyr-531 when oligodendrocytes were differentiated for $3 \mathrm{~d}$ on PDL or laminin substrates and then stimulated with L1-Fc for up to $30 \mathrm{~min}$. The detergent-insoluble fraction contains the membrane microdomains with high lipid order (often called lipid rafts), in which we have shown previously that $\alpha 6 \beta 1$ integrin is localized and within which the majority of Fyn kinase activity is contained. In cells cultured on PDL, the amounts of contactin and Fyn present in this fraction increased after L1-Fc stimulation (Fig. 9A), but in cells cultured on laminin, the majority of contactin and Fyn was present in this fraction throughout (Fig. 9B). On PDL substrates, L1 induced a time-dependent increase in phosphorylation of the positive regulatory site (Tyr420). The negative regulatory site (Tyr-531) was initially highly phosphorylated and was unaffected by L1-Fc stimulation (Fig. 9C). In contrast, when the cells were cultured on laminin, L1-Fc treatment induced a transient increase of both Tyr- 420 and Tyr531 phosphorylation (Fig. 9C). We therefore calculated the "activation ratio," defined as the ratio of the level of phosphorylated Tyr-420 to Tyr-531 (Fig. 9D). This ratio, reflecting Fyn activity, was increased by L1-Fc stimulation of cells on both PDL and laminin. A higher activity level of Fyn was observed on laminin compared with PDL attributable to the lower phosphorylation levels of Tyr-531.

To confirm that the increase in Tyr- 420 phosphorylation after the addition of L1-Fc represented phosphorylation of Fyn, not any other Src-family kinase, we repeated the analysis using phospho-specific antibodies after immunoprecipitation of the lysates with anti-Fyn antibodies. Again, and as expected, L1-Fc induced phosphorylation of Tyr-420, confirming that this represents a modification of Fyn (Fig. 9E). Also, no increase in phosphorylation was observed with a control Fc protein, showing that the effect was attributable to the L1 part of the L1-Fc chimera, not recognition and signaling by glial $\mathrm{Fc}$ receptors (Fig. $9 F$ ).

Finally, the function of contactin in the signaling complex was assessed after siRNA-mediated knockdown of contactin. The knockdown had no effect on the level of Fyn in the insoluble fraction (Fig. 10A) but completely abolished L1-induced phosphorylation of Tyr- 420 after treatment with L1-Fc. When contactin was knocked down in the presence of laminin, both the increased phosphorylation of Tyr-420 and Tyr-531 after L1-Fc stimulation was reduced. The lower phosphorylation level observed for cells cultured on laminin was minimally effected (Fig. $10 \mathrm{~B})$. These results confirm that contactin is essential for L1regulated activation of Fyn, both when cells are exposed to L1 alone or when laminin and L1 are present.

\section{Discussion}

We have identified contactin as a novel integrin-associated protein in oligodendrocytes, and we have shown that these two molecules form a functional signaling unit by their regulation of the Src family kinase Fyn. Integration of signals from laminin in the extracellular matrix and axonal L1, which bind to the contactinintegrin complex, is achieved by differential phosphorylation of the two regulatory tyrosines of Fyn. The inhibitory C-terminal tyrosine (Tyr-531) is dephosphorylated after laminin-integrin interaction (Colognato et al., 2004), which enables the Src family kinase to become fully activated by phosphorylation of the activating tyrosine (Tyr-420). We here show that the interaction of contactin with L1 promotes this phosphorylation of Tyr-420 (Fig. 11A). When both ligands are presented to the oligodendrocytes, a transient increase in phosphorylation of both tyrosines is observed. However, this still leads to an increase in Fyn activity, as evidenced by the ratio of Tyr- 420 to Tyr-531 phosphorylation and, as discussed below, may be important in enabling a dynamic balance of phosphorylation/dephosphorylation required for reversible control of Fyn signaling (Fig. 11B).

Coamplification of signals from the extracellular matrix and 
A

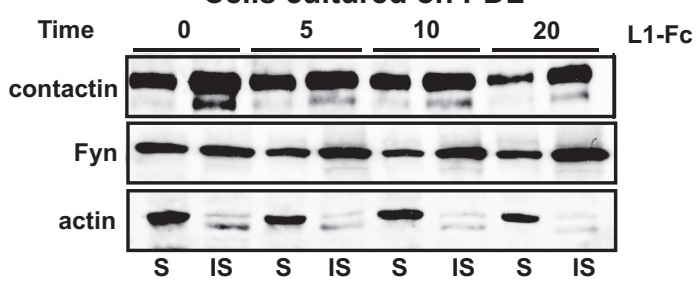

B

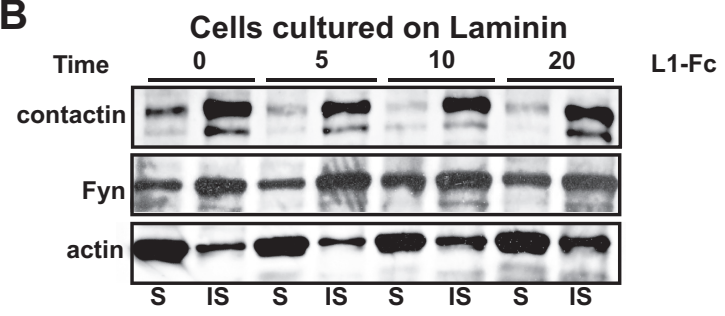

C

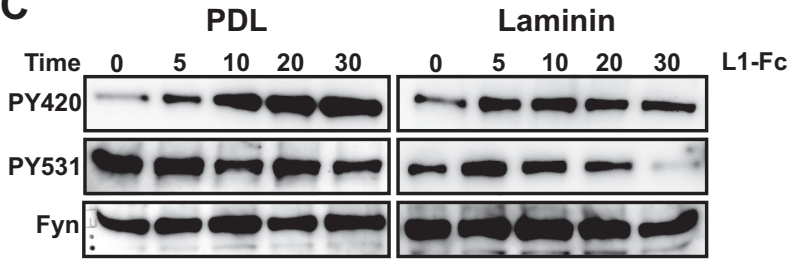

D

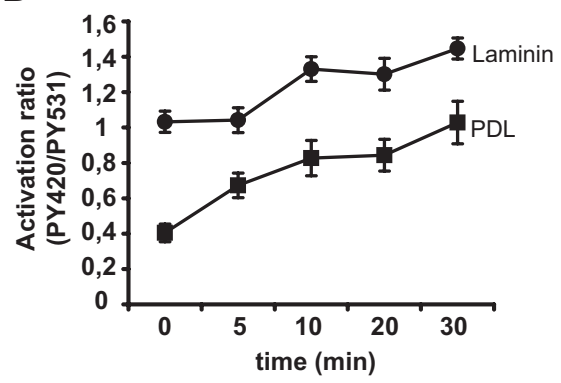

E

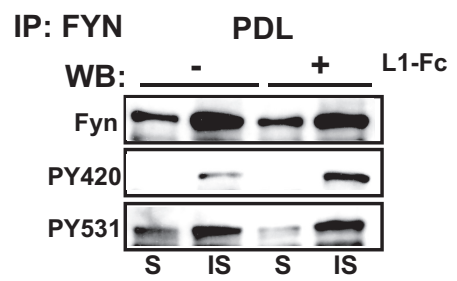

$\mathbf{F}$

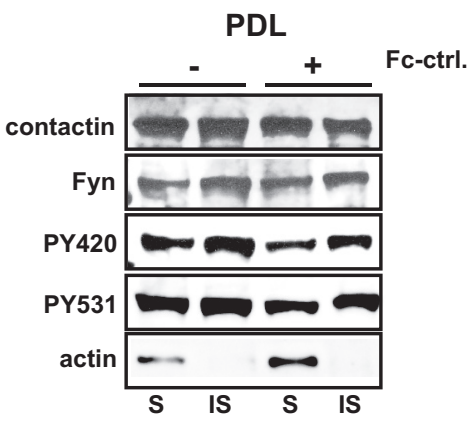

Figure 9. The combined effect of laminin and $\mathrm{L} 1$ is required for maximal Fyn activation. $A$, Expression and solubility of contactin and Fyn in lysates from oligodendrocytes differentiated for $3 \mathrm{~d}$ on PDL and then stimulated with L1-Fc for different times, as indicated. Detection was performed by Western blotting using actin as a loading control. S, Triton X-100-soluble fraction; IS, Triton $X$-100-insoluble fraction. $\boldsymbol{B}, A$ in $\boldsymbol{A}$ but using cell lysates from oligodendrocytes cultured on laminin. Note the greater amount of contactin and Fyn in the Triton X-100-insoluble fraction compared with cells plated on PDL, shown in A. C, Phosphorylation of Fyn at different time points after stimulation with L1-Fc. The cells were cultured on PDL or laminin, as indicated. On PDL, L1 induces a time-dependent increase in Tyr-420 phosphorylation. On laminin, Tyr-531 is less phosphorylated, and L1-Fc induces a timedependent increase in both Tyr-420 and Tyr-531 phosphorylation, decreasing to the basal level after $20 \mathrm{~min}$. D, The Fyn activation ratio, calculated as the ratio of phosphorylated Tyr-420/Tyr-531. Values are means \pm SD of three independent experiments. $\boldsymbol{E}$ Immunoprecipitation (IP) of oligodendrocyte lysates using a Fyn-specific antibody after 0 or 10 min stimulation with L1-Fc (1 $\mu \mathrm{g} / \mathrm{ml})$. Phosphorylation was evaluated by Western blotting (WB) using antibodies specific for phosphorylated Tyr-420 and phosphorylated Tyr-531. $\boldsymbol{F}$, Expression of contactin and Fyn and the phosphorylation level of Fyn at Tyr-420 and
L1 has been described in studies on cell migration and axon outgrowth (Felsenfeld et al., 1994; Treubert and Brümmendorf, 1998; Thelen et al., 2002), but the mechanism has not been defined previously. Here we demonstrate coamplification in oligodendrocyte survival signaling, and our data on the activation of Fyn provide a mechanism to explain these present and previous observations. They also significantly extend our previous knowledge on how axon contact mediates oligodendrocyte survival by answering two questions. First, how is Fyn activated by axonal contact? Second, given that laminins are present in the extracellular matrix of the CNS, and therefore may remain accessible even when an axon is myelinated, how is oligodendrocyte survival precisely linked to the axolemmal contact that precedes myelination? The identification of contactin as an integrin-associated surface molecule, required for phosphorylation of the activating tyrosine in Fyn, provides an answer to both questions as well as extends previous findings that contactin clustering increases Fyn phosphorylation (Krämer et al., 1997). L1 is expressed on axons in the developing CNS with a peak expression at the onset of myelination (Joosten and Gribnau, 1989). We therefore suggest that the copresentation of both the extracellular matrix signal and L1 ensures the precision required to tightly link oligodendrocyte survival to axolemmal contact and, therefore, the presence of available unmyelinated axons (Fig. $11 C)$.

The use of myelinating cocultures confirmed the role of L1 in oligodendrocyte survival and also showed a considerably enhanced degree of myelination after the addition of soluble L1-Fc. This latter finding is in contrast to previous data from mixed CNS cultures, in which L1-Fc reduced myelination (Barbin et al., 2004). This may reflect differences in the neurons used in the two studies and, consequently, differences in the expression of L1 on the axons, possibly resulting from different levels of electrical activity (Itoh et al., 1995; Stevens et al., 1998).

As we observe with L1, IGF-1 and neuregulin also increase oligodendrocyte survival and myelination (Barres et al., 1992;

$\leftarrow$

Tyr-531 in lysates from oligodendrocyte differentiated for $3 \mathrm{~d}$ on PDL and then stimulated with an Fc control for 0 or $10 \mathrm{~min}$. Detection was performed by Western blotting using actin as a loading control. Note that no changes in phosphorylation occur. 
A

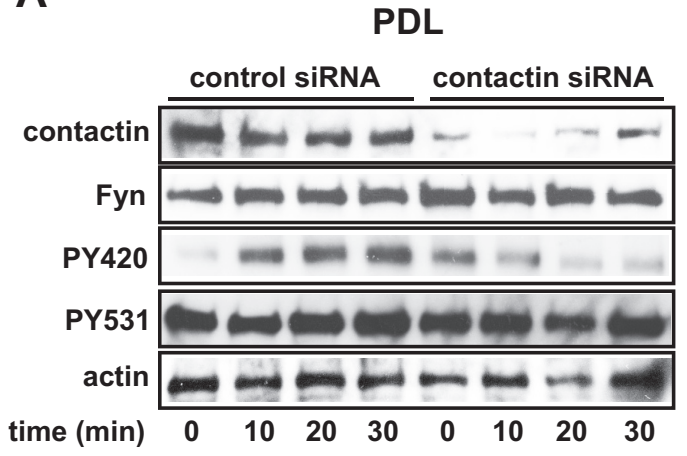

B

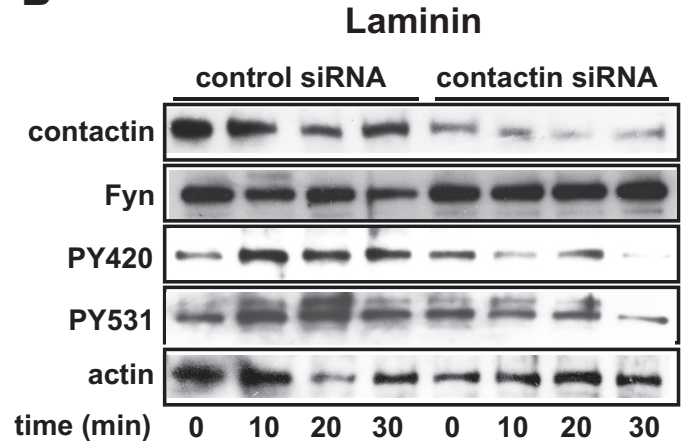

Figure 10. Contactin is required for $\mathrm{L} 1$ - and laminin-induced Fyn activation. $A$, Expression of contactin and Fyn and the level of Fyn phosphorylation in oligodendrocytes transfected with control or contactin siRNA duplexes, followed by differentiation for $3 \mathrm{~d}$ on PDL and then stimulated with L1-Fc for different times, as indicated. Detection was performed by Western blotting after cell lysis, and actin was used as a loading control. No L1-Fc-induced increase in Tyr-420 phosphorylation was observed in cells transfected with contactin siRNA. $\boldsymbol{B}$, Expression of contactin and Fyn and the level of Fyn phosphorylation in lysates from oligodendrocytes transfected with control or contactin siRNA duplexes. After transfection, the cells were allowed to differentiate for $3 \mathrm{~d}$ on laminin and then stimulated with L1-Fc for different times, as indicated. Detection was performed by Western blotting using actin as a loading control. Reduced levels of L1-induced Tyr-420 phosphorylation and Tyr-531 phosphorylation are observed in the contactin knockdown cells.

Carson et al., 1993; Fernandez et al., 2000; Brinkmann et al., 2008). However, not all factors have positive effects on both because PDGF, which is a well described survival factor (Barres et al., 1992), stalls myelination (Wang et al., 2007). This important result shows that cell survival is not always linked to increased myelination. Rather, oligodendrocyte survival and myelination must be regulated by two separate mechanisms, and a particular factor may therefore have different functions at different stages of oligodendrocyte development.

Before myelination, the oligodendrocyte precursors undergo a period of extensive process extension and retraction (Kirby et al., 2006), and myelination itself is associated with profound shape changes in the oligodendrocyte. In this process, the cooperative effects of integrin and contactin on Fyn phosphorylation may also play a key role. Thus, our results have interesting parallels to changes observed in the early phases of cell spreading, in which phosphorylation of the inhibitory tyrosine of Src has been shown to be important for the dynamic turnover of focal adhesions and for normal cell adhesion and spreading (Vielreicher et al., 2007). Moreover, L1 regulation of integrin endocytosis has been suggested to be important for regulation of integrinmediated cell adhesion required for migration (Panicker et al.,
2006; Maness and Schachner, 2007). Although it is unknown whether endocytosis of the $\beta 1$-integrins is coupled to the recycling of the activity of Src family kinases, these results suggest that integration of L1 and extracellular matrix signals enables a dynamic change in cell adhesion as required for process motility and myelination.

In keeping with a role for the interaction between axonal L1 and oligodendrocyte contactin in myelination, the levels of L1 peak at the time of myelination, and the protein is found primarily on the axon rather than on the dendrites or the cell body of neurons (Joosten and Gribnau, 1989; Persohn and Schachner, 1990). L1 is shed from the surface of cells by metalloproteinasemediated cleavage (Beer et al., 1999). Importantly, blocking L1 cleavage, by means of metalloproteinase inhibitors, prevents the migration-promoting effect of overexpressed full-length L1, suggesting that only the shed form of L1 is active (Mechtersheimer et al., 2001). A dramatic increase in the amount of cleaved L1 is observed in the brain at the time of myelination, whereas fulllength $\mathrm{L} 1$ is the predominant form before myelination (Mechtersheimer et al., 2001). Together, these observations suggest that L1 is cleaved from the surface of axons as myelination progresses and that the shed form of L1, mimicked by L1-Fc added to the cocultures, rather than the transmembrane form, is the physiological stimulus to initiate myelination. This, in turn, suggests a working model in which axonal L1 is proteolytically cleaved at the leading edge of the growing oligodendrocyte process. Such surface shedding of L1 enhances movement of the process on and around the axon by dynamic regulation of Fyn phosphorylation, as described above. Once the tip of the process has grown over an area of axolemma, however, the lack of L1, resulting from proteolytic cleavage, reduces the level of Fyn activation, so promoting the more stable axoglial contact required for the later stages of myelination (Fig. 11D).

There are no reports of any abnormalities in CNS myelination caused by a loss of L1. L1 knock-out mice show abnormal brain development with a reduction in brain size (Dahme et al., 1997), defects in axonal guidance in the corticospinal tract (Cohen et al., 1998), and enlarged lateral ventricles (Dahme et al., 1997). Likewise, myelination abnormalities have also not been described in humans with two diseases caused by L1 gene mutations, X-linked hydrocephalus (XLH) and hereditary spastic paraplegia (SPG1). However, hypoplasia of white matter tracts occurs in children with XLH (Yamasaki et al., 1995; Sztriha et al., 2002), and patients with SPG1 have a similar phenotype to those with SPG2 caused by mutations in the gene encoding the myelin protein PLP (proteolipid protein) (Kobayashi et al., 1996). In contrast to the CNS, the role of L1 in myelination in the PNS is well established. Abnormal myelination with Schwann cells failing to ensheath smalldiameter axons appropriately was observed in the L1 knock-out mouse (Dahme et al., 1997). This phenotype is caused by a loss of axonal L1 (Haney et al., 1999). Furthermore, in cocultures of DRG neurons and Schwann cells, blocking L1 antibodies can prevent myelination by inhibiting the wrapping process (Wood et al., 1990). More recent data suggests that the effect of L1 on myelination in the PNS is mediated though heterophilic interactions with an unknown receptor on the Schwann cells, possibly an integrin, based on the lack of any enhancement of integrin signaling by a L1 variant that lacks the sixth Ig domain (Itoh et al., 2005). However, this domain also contains residues known to be important for binding of contactin and axonin (De Angelis et al., 1999) and could therefore also represent an example of an integrin-contactin interaction, as described here.

A recent study shows that the L1-contactin interaction also 
has a function in the regulation of MBP translation in an oligodendroglia cell line (White et al., 2008), an effect that was linked to Fyn phosphorylation. Our identification of contactin as a novel integrinassociated protein provides a mechanism for how signals can be transmitted though this GPI-anchored protein. This is further extended by our observation that a combination of extracellular matrix and axonal signals is required for maximal Fyn activation. Hence, several lines of evidence point to a central role for contactin in CNS myelination. Analysis of myelination in mice lacking glial contactin, as well as identification of the associated kinases and phosphatases in these cells, are therefore important questions for future studies.

\section{References}

Barbin G, Aigrot MS, Charles P, Foucher A, Grumet M, Schachner M, Zalc B, Lubetzki C (2004) Axonal cell adhesion molecule L1 in myelination. Neuron Glia Biol 1:65-72.

Barres BA, Hart IK, Coles HS, Burne JF, Voyvodic JT, Richardson WD, Raff MC (1992) Cell death and control of cell survival in the oligodendrocyte lineage. Cell 70:31-46.

Barres BA, Jacobson MD, Schmid R, Sendtner M, Raff MC (1993) Does oligodendrocyte survival depend on axons? Curr Biol 3:489-497.

Beer S, Oleszewski M, Gutwein P, Geiger C, Altevogt P (1999) Metalloproteinase-mediated release of the ectodomain of $\mathrm{L} 1$ adhesion molecule. J Cell Sci 112:2667-2675.

Benninger Y, Colognato H, Thurnherr T, Franklin RJ, Leone DP, Atanasoski S, Nave KA, ffrenchConstant C, Suter U, Relvas JB (2006) $\beta 1$ Integrin signaling mediates premyelinating oligodendrocyte survival but is not required for CNS myelination and remyelination. J Neurosci 26:7665-7673.

Bolte S, Cordelières FP (2006) A guided tour into subcellular colocalization analysis in light microscopy. J Microsc 224:213-232.

Bottenstein JE, Sato GH (1979) Growth of a rat neuroblastoma cell line in serum-free supplemented medium. Proc Natl Acad Sci U S A 76:514-517.

Brinkmann BG, Agarwal A, Sereda MW, Garratt AN, Müller T, Wende H, Stassart RM, Nawaz S, Humml C, Velanac V, Radyushkin K, Goebbels S, Fischer TM, Franklin RJ, Lai C, Ehrenreich H, Birchmeier C, Schwab MH, Nave KA (2008) Neuregulin-1/ErbB signaling serves distinct functions in myelination of the peripheral and central nervous system. Neuron 59:581-595.

Carson MJ, Behringer RR, Brinster RL, McMorris FA (1993) Insulin-like growth factor I increases brain growth and central nervous system myelination in transgenic mice. Neuron 10:729-740.

Chan JR, Watkins TA, Cosgaya JM, Zhang C, Chen L, Reichardt LF, Shooter EM, Barres BA (2004) NGF controls axonal receptivity to myelination by Schwann cells or oligodendrocytes. Neuron 43:183-191.

Chun SJ, Rasband MN, Sidman RL, Habib AA, Vartanian T (2003) Integrinlinked kinase is required for laminin-2-induced oligodendrocyte cell spreading and CNS myelination. J Cell Biol 163:397-408.

Cohen NR, Taylor JS, Scott LB, Guillery RW, Soriano P, Furley AJ (1998) Errors in corticospinal axon guidance in mice lacking the neural cell adhesion molecule L1. Curr Biol 8:26-33.

Colognato H, Baron W, Avellana-Adalid V, Relvas JB, Baron-Van Evercooren A, Georges-Labouesse E, ffrench-Constant C (2002) CNS integrins switch growth factor signalling to promote target-dependent survival. Nat Cell Biol 4:833-841.
B

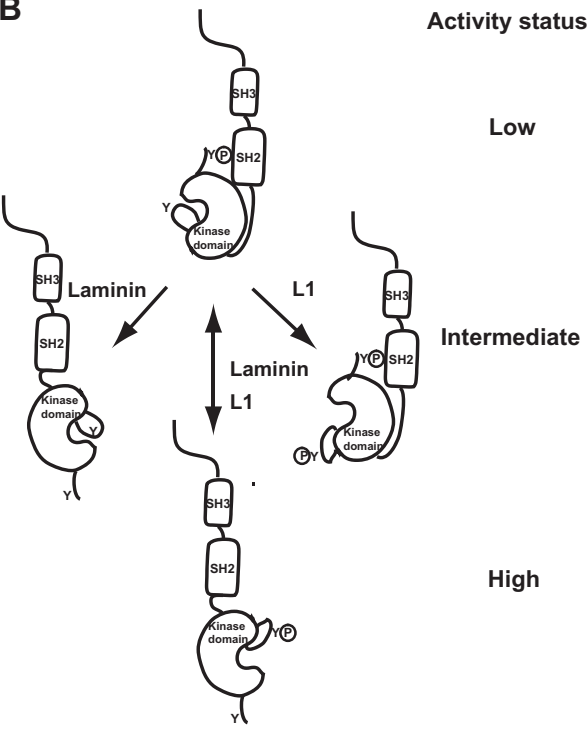

D

Wrapping

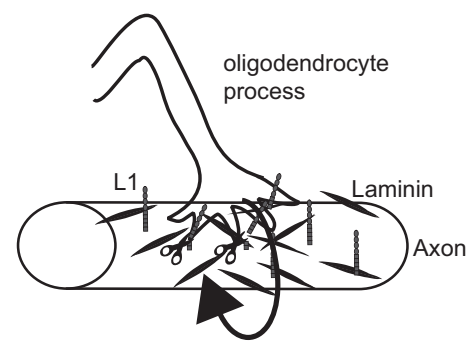

Figure 11. Fyn integrates signals from multiple sources to enhance oligodendrocyte survival and myelination. $\boldsymbol{A}$, We propose the existence of an integrative signaling unit present on the surface of oligodendrocytes, composed of laminin-binding integrin

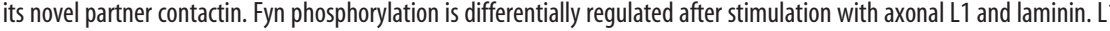
the axonal surface increase survival in combination with soluble growth factors, representing a molecular mechanism whereby (low) growth factor concentrations. D, The presence of soluble L1, cleaved from the axon surface, enhances myelination, possibly by a mechanism that allows a dynamic movement of the oligodendrocyte process around the axon. See Discussion for details of this model.

Colognato H, Ramachandrappa S, Olsen IM, ffrench-Constant C (2004) Integrins direct Src family kinases to regulate distinct phases of oligodendrocyte development. J Cell Biol 167:365-375.

Dahme M, Bartsch U, Martini R, Anliker B, Schachner M, Mantei N (1997) Disruption of the mouse L1 gene leads to malformations of the nervous system. Nat Genet 17:346-349.

De Angelis E, MacFarlane J, Du JS, Yeo G, Hicks R, Rathjen FG, Kenwrick S, Brümmendorf T (1999) Pathological missense mutations of neural cell adhesion molecule L1 affect homophilic and heterophilic binding activities. EMBO J 18:4744-4753.

De Benedictis L, Bizzoca A, Corsi P, Albieri I, Consalez GG, Gennarini G (2006) Activation profile of the F3/Contactin gene in the developing mouse cerebellum. Mol Cell Neurosci 32:403-418.

Felsenfeld DP, Hynes MA, Skoler KM, Furley AJ, Jessell TM (1994) TAG-1 can mediate homophilic binding, but neurite outgrowth on TAG-1 requires an L1-like molecule and beta 1 integrins. Neuron 12:675-690.

Fernandez PA, Tang DG, Cheng L, Prochiantz A, Mudge AW, Raff MC (2000) Evidence that axon-derived neuregulin promotes oligodendrocyte survival in the developing rat optic nerve. Neuron 28:81-90.

Frost EE, Buttery PC, Milner R, ffrench-Constant C (1999) Integrins mediate a neuronal survival signal for oligodendrocytes. Curr Biol 9:1251-1254

Gennarini G, Cibelli G, Rougon G, Mattei MG, Goridis C (1989) The mouse 
neuronal cell surface protein F3: a phosphatidylinositol-anchored member of the immunoglobulin superfamily related to chicken contactin. J Cell Biol 109:775-788.

Gonfloni S, Weijland A, Kretzschmar J, Superti-Furga G (2000) Crosstalk between the catalytic and regulatory domains allows bidirectional regulation of Src. Nat Struct Biol 7:281-286.

Goto J, Tezuka T, Nakazawa T, Sagara H, Yamamoto T (2008) Loss of Fyn tyrosine kinase on the C57BL/6 genetic background causes hydrocephalus with defects in oligodendrocyte development. Mol Cell Neurosci 38:203-212.

Haney CA, Sahenk Z, Li C, Lemmon VP, Roder J, Trapp BD (1999) Heterophilic binding of L1 on unmyelinated sensory axons mediates Schwann cell adhesion and is required for axonal survival. J Cell Biol 146:1173-1184.

Hubbard SR (1999) Src autoinhibition: let us count the ways. Nat Struct Biol 6:711-714.

Itoh K, Stevens B, Schachner M, Fields RD (1995) Regulated expression of the neural cell adhesion molecule L1 by specific patterns of neural impulses. Science 270:1369-1372.

Itoh K, Fushiki S, Kamiguchi H, Arnold B, Altevogt P, Lemmon V (2005) Disrupted Schwann cell-axon interactions in peripheral nerves of mice with altered L1-integrin interactions. Mol Cell Neurosci 30:624-629.

Joosten EA, Gribnau AA (1989) Immunocytochemical localization of cell adhesion molecule L1 in developing rat pyramidal tract. Neurosci Lett 100:94-98.

Kirby BB, Takada N, Latimer AJ, Shin J, Carney TJ, Kelsh RN, Appel B (2006) In vivo time-lapse imaging shows dynamic oligodendrocyte progenitor behavior during zebrafish development. Nat Neurosci 9:1506-1511.

Kobayashi H, Garcia CA, Alfonso G, Marks HG, Hoffman EP (1996) Molecular genetics of familial spastic paraplegia: a multitude of responsible genes. J Neurol Sci 137:131-138.

Krämer EM, Koch T, Niehaus A, Trotter J (1997) Oligodendrocytes direct glycosyl phosphatidylinositol-anchored proteins to the myelin sheath in glycosphingolipid-rich complexes. J Biol Chem 272:8937-8945.

Lee KK, de Repentigny Y, Saulnier R, Rippstein P, Macklin WB, Kothary R (2006) Dominant-negative betal integrin mice have region-specific myelin defects accompanied by alterations in MAPK activity. Glia 53:836-844.

Liang X, Draghi NA, Resh MD (2004) Signaling from integrins to Fyn to Rho family GTPases regulates morphologic differentiation of oligodendrocytes. J Neurosci 24:7140-7149.

Maness PF, Schachner M (2007) Neural recognition molecules of the immunoglobulin superfamily: signaling transducers of axon guidance and neuronal migration. Nat Neurosci 10:19-26.

Martini R, Schachner M (1986) Immunoelectron microscopic localization of neural cell adhesion molecules (L1, N-CAM, and MAG) and their shared carbohydrate epitope and myelin basic protein in developing sciatic nerve. J Cell Biol 103:2439-2448.

McCarthy KD, de Vellis J (1980) Preparation of separate astroglial and oligodendroglial cell cultures from rat cerebral tissue. J Cell Biol 85:890-902.

Mechtersheimer S, Gutwein P, Agmon-Levin N, Stoeck A, Oleszewski M, Riedle S, Postina R, Fahrenholz F, Fogel M, Lemmon V, Altevogt P (2001) Ectodomain shedding of L1 adhesion molecule promotes cell migration by autocrine binding to integrins. J Cell Biol 155:661-673.

Michailov GV, Sereda MW, Brinkmann BG, Fischer TM, Haug B, Birchmeier C, Role L, Lai C, Schwab MH, Nave KA (2004) Axonal neuregulin-1 regulates myelin sheath thickness. Science 304:700-703.

Milner R, ffrench-Constant C (1994) A developmental analysis of oligoden- droglial integrins in primary cells: changes in alpha v-associated beta subunits during differentiation. Development 120:3497-3506.

Panicker AK, Buhusi M, Erickson A, Maness PF (2006) Endocytosis of betal integrins is an early event in migration promoted by the cell adhesion molecule L1. Exp Cell Res 312:299-307.

Persohn E, Schachner M (1990) Immunohistological localization of the neural adhesion molecules L1 and N-CAM in the developing hippocampus of the mouse. J Neurocytol 19:807-819.

Ranscht B (1988) Sequence of contactin, a 130-kD glycoprotein concentrated in areas of interneuronal contact, defines a new member of the immunoglobulin supergene family in the nervous system. J Cell Biol 107:1561-1573.

Sperber BR, Boyle-Walsh EA, Engleka MJ, Gadue P, Peterson AC, Stein PL, Scherer SS, McMorris FA (2001) A unique role for Fyn in CNS myelination. J Neurosci 21:2039-2047.

Stevens B, Tanner S, Fields RD (1998) Control of myelination by specific patterns of neural impulses. J Neurosci 18:9303-9311.

Sztriha L, Vos YJ, Verlind E, Johansen J, Berg B (2002) X-linked hydrocephalus: a novel missense mutation in the L1CAM gene. Pediatr Neurol 27:293-296.

Taveggia C, Zanazzi G, Petrylak A, Yano H, Rosenbluth J, Einheber S, Xu X, Esper RM, Loeb JA, Shrager P, Chao MV, Falls DL, Role L, Salzer JL (2005) Neuregulin-1 type III determines the ensheathment fate of axons. Neuron 47:681-694.

Thelen K, Kedar V, Panicker AK, Schmid RS, Midkiff BR, Maness PF (2002) The neural cell adhesion molecule L1 potentiates integrin-dependent cell migration to extracellular matrix proteins. J Neurosci 22:4918-4931.

Trapp BD, Nishiyama A, Cheng D, Macklin W (1997) Differentiation and death of premyelinating oligodendrocytes in developing rodent brain J Cell Biol 137:459-468.

Treubert U, Brümmendorf T (1998) Functional cooperation of beta1integrins and members of the Ig superfamily in neurite outgrowth induction. J Neurosci 18:1795-1805.

Umemori H, Sato S, Yagi T, Aizawa S, Yamamoto T (1994) Initial events of myelination involve Fyn tyrosine kinase signalling. Nature 367:572-576.

van den Pol AN, Kim WT (1993) NILE/L1 and NCAM-polysialic acid expression on growing axons of isolated neurons. J Comp Neurol 332:237-257.

Vielreicher M, Harms G, Butt E, Walter U, Obergfell A (2007) Dynamic interaction between $\mathrm{Src}$ and $\mathrm{C}$-terminal Src kinase in integrin alphaIIbbeta3-mediated signaling to the cytoskeleton. J Biol Chem 282:33623-33631.

Wang Z, Colognato H, ffrench-Constant C (2007) Contrasting effects of mitogenic growth factors on myelination in neuron-oligodendrocyte cocultures. Glia 55:537-545.

White R, Gonsior C, Krämer-Albers EM, Stöhr N, Hüttelmaier S, Trotter J (2008) Activation of oligodendroglial Fyn kinase enhances translation of mRNAs transported in hnRNP A2-dependent RNA granules. J Cell Biol 181:579-586.

Winckler B, Forscher P, Mellman I (1999) A diffusion barrier maintains distribution of membrane proteins in polarized neurons. Nature 397:698-701.

Wood PM, Schachner M, Bunge RP (1990) Inhibition of Schwann cell myelination in vitro by antibody to the L1 adhesion molecule. J Neurosci 10:3635-3645.

Yamasaki M, Arita N, Hiraga S, Izumoto S, Morimoto K, Nakatani S, Fujitani K, Sato N, Hayakawa T (1995) A clinical and neuroradiological study of X-linked hydrocephalus in Japan. J Neurosurg 83:50-55. 